\title{
Optimization of a Joint Economic Lot Size Model for a First-tier Supplier with Sequential Processes Using a Genetic Algorithm
}

\author{
${ }^{1}$ DongJin Jin, ${ }^{1}$ MoonHyeung Lee, ${ }^{1}$ ByungDo Chung \\ ${ }^{1}$ Department of industrial engineering, Yonsei University, Seoul, Republic of KOREA; \\ dj.jin@yonsei.ac.kr; mh_lee@yonsei.ac.kr; bd.chung@yonsei.ac.kr
}

\begin{abstract}
As corporate competition intensifies in the 21st century, optimal in the integrated supply chain is more important than optimization of individual company. Our research examines a series of integrated supply chain systems comprising a single raw material supplier, a first-tier supplier with multiple processes, and a single original equipment manufacturer in the Korean automotive industry. Unlike other papers, we have studied the situation in which the first-tier supplier has an assembly process. We have also analyzed the situation in which the demand for semi-finished products occurs in the first-tier supplier process or in which semi-finished products are purchased from subcontractors and put into production. The objective function is to minimize the sum of production costs, inventory holding costs, ordering costs, and setup costs in the integrated supply chain. To solve this problem, we formulated nonlinear programming, and developed a genetic algorithm. The results showed that using a dynamic lot size is cheaper than using a fixed lot size. In addition, the lower the setup cost, the smaller the lot size, and when a certain level is reached, the lot size will be the same even if the cost changes.
\end{abstract}

Keywords: Integrated supply chain, First-tier supplier, Lot size, Nonlinear programming, Genetic algorith $\mathrm{m}$

\section{Introduction}

The supply chain in the automotive industry comprises raw material suppliers, first-tier suppliers, original equipment manufacturers (OEMs), dealers, and distributors. Supply chain management in the domestic automotive industry is underway to optimize the supply chain structure from manufacturing procurement to delivery. OEMs use just-in-time (JIT) systems to supply the required quantity of parts in a timely manner. However, some first-tier suppliers do not use a JIT system. Consequently, first-tier suppliers are inefficient in terms of production or inventory to avoid problems of OEMs production.

In this study, we analyzed the first-tier supplier of three processes of the blank line, press line, and assembly line of companies manufacturing automobile body parts. Determining the appropriate lot size for each line is very important as it affects efficiency in the manufacturing line and directly affects inventory and production costs. If the production lot size increases, the number of setups decreases. However, a large number of works in process (WIPs) occur, resulting in inefficiency in the supply chain. On the other hand, reducing the size of the production lot reduces inventory. However, the number of setups increases, resulting in process unavailability [12]. The manufacturing industry in Korea, especially 
the automobile industry, thinks that the setup is the cause of productivity deterioration. Among them, replacement work of coils and molds increases the intensity of work. Owing to the nature of these industries, the production lot size cannot be minimized. This study addresses the joint economic lot size problem (JELP), which reflects the process characteristics of first-tier suppliers. Previous research has considered a two-tiered supply chain system that includes only suppliers and distributors. Recently, research has been underway to determine the lot size in a supply chain system with three or more levels. In addition, most previous studies have used two approaches to the JELP methodology. In the first, the heuristic method is used after mathematically proving the optimality condition or convexity to simplify the problem. The second method involves formulating the problem with a mixed integer non-linear programming (MINLP) model and using heuristic methods. We formulate the problem with a non-linear programming (NLP) model in which all decision variables are integers, as in the second method, and we solve the problem using a genetic algorithm. The reason for using integers is that the lot size produced by the first-tier supplier and the number of production and delivery are actually represented as integer values. In addition, the lot used once for production must be fully used.

This study considers the raw material suppliers, first-tier suppliers, and OEMs in the supply chain. The purpose of this study is to determine the lot size that minimizes the cost of the total supply chain, including production, setup, ordering, and inventory holding costs. We also propose a genetic algorithm to solve the NLP problem. This is because the computation time exponentially increases as the number of products or processes increases in the NLP model. In addition, the actual automobile parts manufacturers have the characteristic of making the production plan by using a fixed lot size. Therefore, we compare the total cost of the supply chain based on the actual production lot size of the actual automobile body parts manufacturer and the production lot size obtained by the proposed algorithm.

The remainder of the paper is organized as follows. Section 2 describes the literature review, Section 3 presents the problem definition and assumptions, Section 4 explains the modeling, Section 5 describes the algorithm, and Section 6 presents the experimental results. Finally, Section 7 offers a conclusion.

\section{Literature Review}

The JELP began in 1977 when Goyal [1] began to study a two-stage supply chain that involved only a vendor and a retailer. He proposed a solution to solve this problem, assuming that the producer could produce indefinitely without any restrictions on the production volume. Next, Banerjee [2] investigated problems closer to actual situations by mitigating the assumption that they could produce indefinitely from models such as Goyal. Hill [3] conducted research that restricted the production volume and placed no restrictions on the shipment policy. Alizade et al. [4] covered a supply chain comprising two or more suppliers and retailers in a two-tier supply chain. This study considered demand to be probabilistic or that lead time can be changed. In addition, they considered a situation in which the number of items in the supply chain is more than one.

The following research comprises three echelons of the supply chain. Lee [5] studied a JELP problem by minimizing the sum of the six costs resulting from focusing on the three-level supply chain. He also considered the manufacturer's production batches and the number of orders. Munson and Rosenblatt [6] studied the JELP problem by combining quantity discounts in a three-tier supply chain comprising a single supplier, a single manufacturer, and a single retailer. Wang and Sarker [7] conducted a studied the JIT 
DongJ in Jin, MoonHyeung Lee, ByungDo Chung; Optimization of a Joint Economic Lot Size Model for a First-tier Supplier with Sequential Processes Using a Genetic Algorithm. Transactions on Machine Learning and Artificial Intelligence, Volume 6 No 5 October (2018); pp: 28-42

system operated by kanban and they also analyzed the number of deliveries, the lot size, and the number of appropriate kanban.

The following is a study comprising a three-echelon supply chain with several participants in each stage. Khouja [8] published a paper that expands the thesis of a three-phase supply chain in which one company participates in each stage of Mundson and Rosenblatt. Khouja dealt with the non-serial supply chain and studied a model with several participants. Since then, Jaber and Goyal [9] have discussed order quantity adjustments in a three-echelon supply chain of suppliers, manufacturers, and buyers. Bendaya and AINassar [10] extended the model to one with several participants, reflecting Khouja's assumption that the same size lot is delivered to the next step.

Adeinat and Ventura [11] studied pricing and supplier selection as well as lot size in an integrated supply chain comprising three or more stages. The study showed that the JELP problem is applicable to various problems.

The preceding literature has confirmed that lot size problems in the integrated supply chain have been investigated. Among them, we analyze a three stage supply chain that considers raw material suppliers, first-tier suppliers, and OEMs. The first-tier suppliers comprise blank, press, and assembly processes. We also analyze lot sizes for situations in which there are two lines per process. To the best of our knowledge, there were no studies have considered the assembly line in a supply chain comprising three or more stages and situations where there is a demand or outsourcing item between first-tier suppliers process. Since some automobile parts manufacturers have assembling processes to assemble several parts to form one part, our consideration of assembly lines is an important factor in reflecting the reality.

\section{Problem Definition}

\subsection{Problem Description}

We analyze the lot size in a three stage supply chain comprising raw material suppliers, first-tier suppliers, and OEMs. The integrated supply chain that we consider is shown in Figure 1. A raw material supplier is a company that supplies raw materials for a first-tier supplier. A first-tier supplier is an automobile parts manufacturer. And, we analyze the situation of three lines (blanks, presses and assembly lines) which have two machines exist for each line. The automobile parts manufacturer's blank line is the line of processing raw materials for use in the press line, and the press line is the pre-process of the assembly line that forms the parts. The assembly line is then involved in the process of combining parts to make the finished product. There is also a storage area for all parts between all processes. OEMs have demand for semifinished products and outsourcing materials. Outsourcing materials coming into the manufacturer's storage area can be sent to the customer or the manufacturer's internal processes. Finally, the OEMs represents companies that sell the finished automobile to customers, and first-tier suppliers deliver the quantity to meet the OEMs demand. 


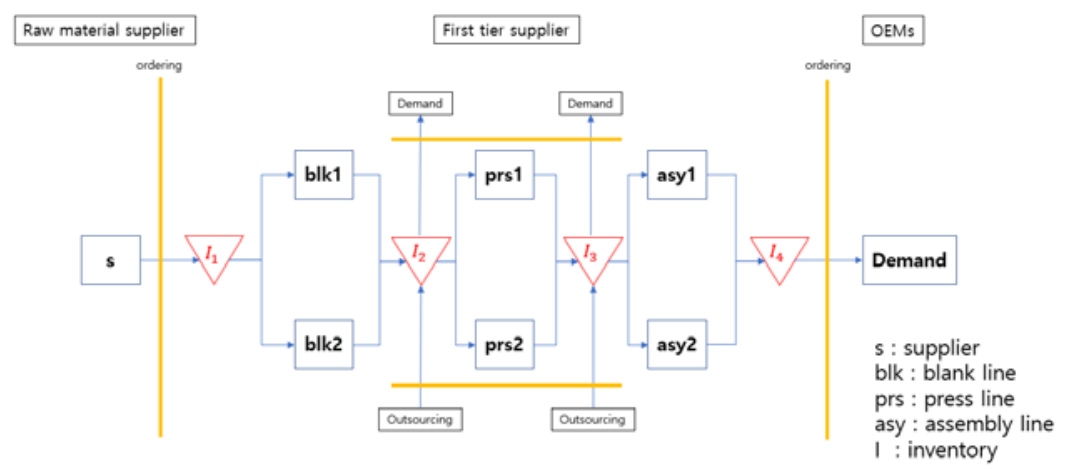

Figure 1. Integrated supply chain

\subsection{Assumption}

The assumptions of this study are as follows:

0 The rates of production and demand are constant

o Raw materials (coils) are not scarce

0 They produce 500 blank sheets using one raw material (coil)

0 In the assembly line, they produce one product per line (considering BOM)

0 There is no delivery lead time

o They do not allow backlogging

o The cost of setup, ordering, holding, and production are the same for each stage

0 Ordering costs occur between the raw material supplier and first-tier supplier and between the first-tier supplier and OEM. For the first-tier supplier, this cost occurs when they receive the product from a subcontractor or when they ship the product to OEM

o If they use a one lot, they should use it completely

\section{Modeling}

\subsection{Model Description}

The following is a description of the mathematical model. The Bill of Material is shown in Figure 2. Each stage item represents the index of the item stored in the stepwise storage area. In Figure 2, the raw material supplier has two items, the blank line has three items, the press line has four items, and the assembly line has two items. Blank item 3 and press item 4 is the outsourcing item from the subcontractor. For example, blank item 1 is created through the blk process using the coil item 1 from the raw material supplier. In Figure 2, blank item 3 and press item 4 refers to the item produced by the subcontractor. It will be stocked in a blank or press storage area. Finally, the assembly line uses the press items 1 and press item 2 to create assembly item 1 . Similarly, press item 3 and press item 4 are used to create assembly item 2 . We want to know the optimal lot size in an integrated supply chain with multiple items. 


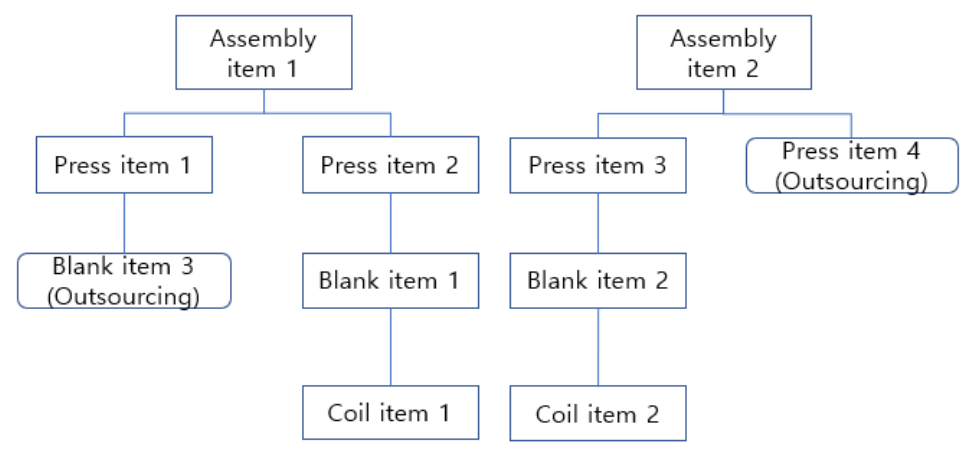

Figure 2. BOM (Bill of Materials) structure

\subsection{Mathematical Model}

The indices, parameters, and decision variables used in the mathematical model are summarized in Tables 1,2 , and 3 . These notations are used to formulate a mathematical model. The decision variables include lot size, the number of production and delivery. These decision variables are also set to integer values because they actually have integer values.

Table 1

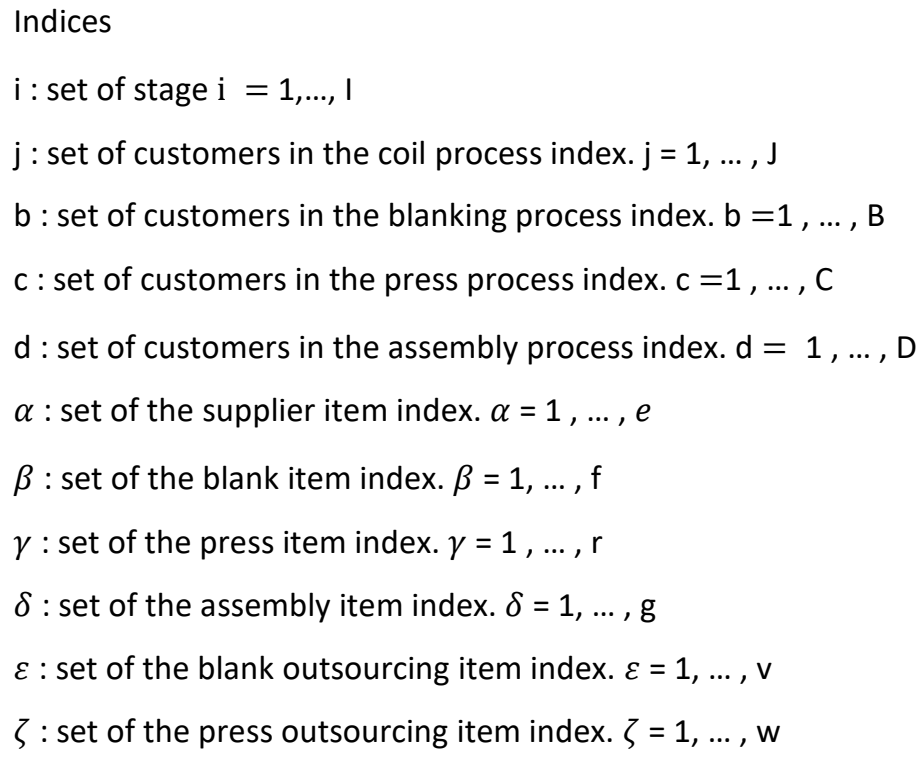

Table 2

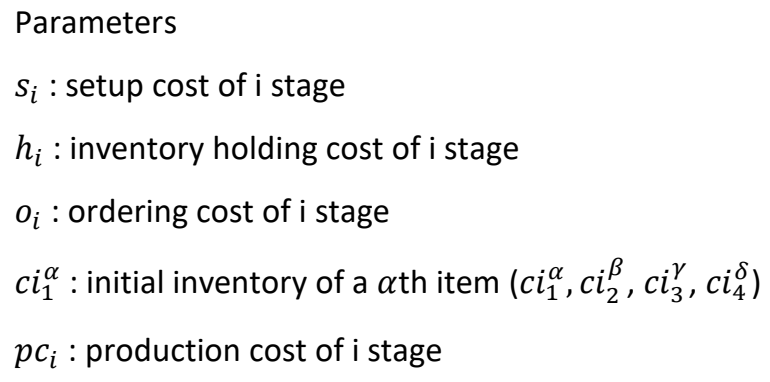




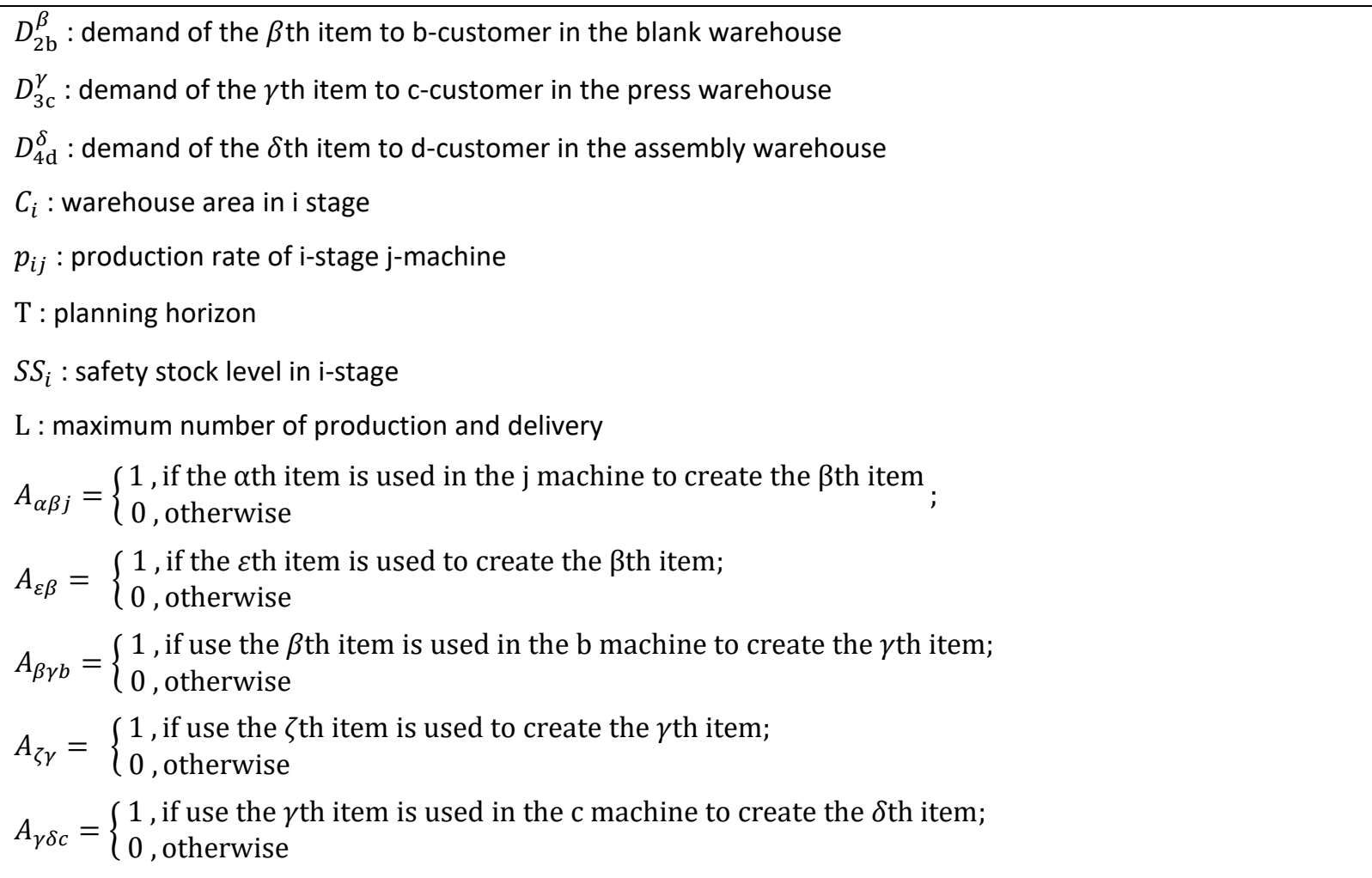

\section{Table 3}

\section{Decision Variables}

$Q_{i}$ : lot size in i-stage

$k_{1}^{\alpha}:$ the number of production for the $\alpha$ th item

$k_{2}^{\alpha \beta j}$ : the number of production for the $\alpha$ th item produced as the $\beta$ th item for the blank j-customer

$k_{2}^{\varepsilon \beta}:$ the number of production for the $\varepsilon$ th item produced as the $\beta$ th item

$k_{3}^{\beta \gamma b}$ : the number of productions for the $\beta$ th item produced as the $\gamma$ th item for the press $b$-customer

$k_{3}^{\zeta \gamma}:$ the number of production for the $\zeta$ th item produced as the $\gamma$ th item

$k_{4}^{\gamma \delta c}$ : the number of production for the $\gamma$ th item produced as the $\delta$ th item for the c-customer

$m_{1 j}^{\alpha}$ : the number of deliveries for the $\alpha$ th item for blank j-machine from the supplier

$m_{2 b}^{\beta}$ : the number of deliveries for the $\beta$ th item for the press b-customer from the blank process

$m_{3 c}^{\gamma}$ : the number of deliveries for the $\gamma$ th item for the assembly c-customer from the press process

$m_{4 d}^{\delta}$ : the number of deliveries for the $\delta$ th item for the d-customer for the assembly process

$u^{c}$ : maximum number of items that come into the same machine to account for BOM.

Next, the objective function is to minimize the total cost, which is the sum of the production cost, setup cost, ordering cost, and inventory holding cost. The costs are expressed as follows.

$$
\text { Total Cost }=\text { Production Cost }+ \text { Setup Cost }+ \text { Ordering Cost }+ \text { Holding Cost }
$$




$$
\begin{aligned}
& \text { Production Cost }=\sum_{\alpha} p c_{1} k_{1}^{\alpha} * Q_{1}+\sum_{\alpha} \sum_{\beta} \sum_{j} p c_{2} * Q_{2} *\left(k_{2}^{\alpha \beta j}+\sum_{\varepsilon} k_{2}^{\varepsilon \beta}\right)+\sum_{\beta} \sum_{\gamma} \sum_{b} p c_{3} * Q_{3} * \\
& \left(k_{3}^{\beta \gamma b}+\sum_{\epsilon} k_{3}^{\epsilon \gamma}\right)+\sum_{\gamma} \sum_{\delta} \sum_{c} p c_{4} * Q_{4} * k_{4}^{\gamma \delta c} \\
& \text { Setup Cost }=\sum_{\alpha} s_{1} k_{1}^{\alpha}+\sum_{\alpha} \sum_{\beta} \sum_{j} s_{2} *\left(k_{2}^{\alpha \beta j}+\sum_{\varepsilon} k_{2}^{\varepsilon \beta}\right)+\sum_{\beta} \sum_{\gamma} \sum_{b} s_{3} *\left(k_{3}^{\beta \gamma b}+\sum_{\epsilon} k_{3}^{\epsilon \gamma}\right)+ \\
& \sum_{\gamma} \sum_{\delta} \sum_{c} s_{4} * k_{4}^{\gamma \delta c} \\
& \text { Ordering Cost }=\sum_{\alpha} o_{1} * k_{1}^{\alpha}+\left\{\sum_{b} \sum_{\beta} o_{2} * m_{2 b}^{\beta}+\sum_{\varepsilon} \sum_{\beta} o_{2} * k_{2}^{\varepsilon \beta}\right\}+\left\{\sum_{c} \sum_{\gamma} o_{3} * m_{3 c}^{\gamma}+\right. \\
& \left.\sum_{\zeta} \sum_{\gamma} o_{3} * k_{3}^{\zeta \gamma}\right\}+\sum_{d} \sum_{\delta} o_{4} * m_{4 d}^{\delta} \\
& \text { Holding Cost }=\sum_{\alpha}\left\{2 c i_{1}^{\alpha}+Q_{1}\left(k_{1}^{\alpha}-\sum_{j} m_{1 j}^{\alpha}\right)\right\} \frac{h_{1}}{2}+\sum_{\beta}\left\{2 c i_{2}^{\beta}+Q_{2}\left(\sum_{\alpha} \sum_{j} k_{2}^{\alpha \beta j}+\sum_{\varepsilon} k_{2}^{\varepsilon \beta}-\right.\right. \\
& \left.\left.\sum_{b} m_{2 b}^{\beta}\right)\right\} \frac{h_{2}}{2}+\sum_{\gamma}\left\{2 c i_{3}^{\gamma}+Q_{3}\left(\sum_{\beta} \sum_{b} k_{3}^{\beta \gamma b}+\sum_{\zeta} k_{3}^{\zeta \gamma}-\sum_{c} m_{3 c}^{\gamma}\right)\right\} \frac{h_{3}}{2}+ \\
& \sum_{\delta}\left\{2 c i_{4}^{\delta}+Q_{4}\left(\sum_{\gamma} \sum_{c} k_{4}^{\gamma \delta c}-\sum_{d} m_{4 d}^{\delta}\right)\right\} \frac{h_{4}}{2}
\end{aligned}
$$

In Equation (1), the objective function is expressed as the sum of the production cost (2), setup cost (3), ordering cost (4), and inventory holding cost (5) included in the integrated supply chain. The production and inventory holding costs are calculated by the number of production, and the remaining costs are by the number of production and delivery. The production cost is calculated by multiplying production volume and production costs per unit. The setup cost is calculated by multiplying the number of production per process by the setup cost per lot. The ordering cost occurs between raw material suppliers and first-tier suppliers, as well as between first-tier suppliers and OEMs. The order cost is calculated as the number of production and shipments multiplied by the order cost per lot in this relationship. The inventory holding cost is calculated by multiplying the average inventory quantity by the inventory holding cost per unit.

Next, the constraints are as follows:

$$
\begin{array}{ll}
\sum_{\alpha}\left\{c i_{1}^{\alpha}+Q_{1}\left(k_{1}^{\alpha}-\sum_{j} m_{1 j}^{\alpha}\right)\right\} \leq C_{1} \\
\sum_{\beta}\left\{c i_{2}^{\beta}+Q_{2}\left(\sum_{\alpha} \sum_{j} k_{2}^{\alpha \beta j}+\sum_{\varepsilon} k_{2}^{\varepsilon \beta}-\sum_{b} m_{2 b}^{\beta}\right)\right\} \leq C_{2} & \\
\sum_{\gamma}\left\{c i_{3}^{\gamma}+Q_{3}\left(\sum_{\beta} \sum_{b} k_{3}^{\beta \gamma b}+\sum_{\zeta} k_{3}^{\zeta \gamma}-\sum_{c} m_{3 c}^{\gamma}\right)\right\} \leq C_{3} & \\
\sum_{\delta}\left\{c i_{4}^{\delta}+Q_{4}\left(\sum_{\gamma} \sum_{c} k_{4}^{\gamma \delta c}-\sum_{d} m_{4 d}^{\delta}\right)\right\} \leq C_{4} & i=2,3 \\
Q_{1}=\frac{Q_{2}}{500}, Q_{i} \geq Q_{i+1} & \forall \alpha \\
c i_{1}^{\alpha}+Q_{1}\left(k_{1}^{\alpha}-\sum_{j} m_{1 j}^{\alpha}\right) \geq S S_{1} & \forall \beta \\
c i_{2}^{\beta}+Q_{2}\left(\sum_{\alpha} \sum_{j} k_{2}^{\alpha \beta j}+\sum_{\varepsilon} k_{2}^{\varepsilon \beta}-\sum_{b} m_{2 b}^{\beta}\right) \geq S S_{2} & \forall \gamma \\
c i_{3}^{\gamma}+Q_{3}\left(\sum_{\beta} \sum_{b} k_{3}^{\beta \gamma b}+\sum_{\zeta} k_{3}^{\zeta \gamma}-\sum_{c} m_{3 c}^{\gamma}\right) \geq S S_{3} & \forall \gamma \\
c i_{4}^{\delta}+Q_{4}\left(\sum_{\gamma} \sum_{c} k_{4}^{\gamma \delta c}-\sum_{d} m_{4 d}^{\delta}\right) \geq S S_{4} & \forall \delta
\end{array}
$$




$$
\begin{aligned}
& m_{1 j}^{\alpha} * Q_{1}=k_{2}^{\alpha \beta j_{*}} Q_{2} \quad \forall \alpha, \beta, j \\
& m_{2 b}^{\beta} * Q_{2}=k_{3}^{\beta \gamma b} * Q_{3} \quad \forall \beta, \gamma, b=1,2 \\
& m_{3 c}^{\gamma} * Q_{3}=k_{4}^{\gamma \delta c} * Q_{4} \quad \forall \gamma, \delta, c=1,2 \\
& \begin{array}{ll}
k_{4}^{\gamma \delta c} \geq u^{c}, u^{c} \geq 0 \quad \forall \gamma, \delta, c
\end{array} \\
& \sum_{\alpha} k_{1}^{\alpha *} Q_{1} \leq P_{1} T \text {, } \\
& \sum_{\alpha} \sum_{\beta} k_{2}^{\alpha \beta j} * Q_{2} \leq P_{2 j} T \quad \forall j \\
& \sum_{\beta} \sum_{\gamma} k_{3}^{\beta \gamma b} * Q_{3} \leq P_{3 b} T \quad \mathrm{~b}=1,2 \\
& \sum_{\gamma} \sum_{\delta} k_{4}^{\gamma \delta c} * Q_{4} \leq P_{4 c} T \quad \mathrm{c}=1,2 \\
& m_{2 b}^{\beta} * Q_{2} \geq D_{2 b}^{\beta} \quad \forall \beta, b=3 \\
& m_{3 c}^{\gamma} * Q_{3} \geq D_{3 c}^{\gamma} \quad \forall \gamma, c=3 \\
& m_{4 d}^{\delta} * Q_{4} \geq D_{4 d}^{\delta} \quad \forall \delta, d=1 \\
& k_{2}^{\alpha \beta j}=0, m_{1 j}^{\alpha}=0 \quad A_{\alpha \beta j}=0 \\
& k_{2}^{\varepsilon \beta}=0, \quad A_{\varepsilon \beta}=0 \\
& k_{3}^{\beta \gamma b}=0, m_{2 b}^{\beta}=0 \quad A_{\beta \gamma b}=0 \\
& k_{3}^{\zeta \gamma}=0 \quad A_{\zeta \gamma}=0 \\
& k_{4}^{\gamma \delta c}=0, m_{3 c}^{\gamma}=0 \quad A_{\gamma \delta c}=0 \\
& k_{1}^{\alpha}, k_{2}^{\alpha \beta j}, k_{2}^{\varepsilon \beta}, k_{3}^{\beta \gamma b}, k_{3}^{\zeta \gamma}, k_{4}^{\gamma \delta c}, m_{1 j}^{\alpha}, m_{2 b}^{\beta}, m_{3 c}^{\gamma}, m_{4 d}^{\delta} \leq \\
& \mathrm{L} \quad \text { integer, } \forall \alpha, \beta, \gamma, \delta, j, b, c, d \\
& k_{1}^{\alpha}, k_{2}^{\alpha \beta j}, k_{2}^{\varepsilon \beta}, k_{3}^{\beta \gamma b}, k_{3}^{\zeta \gamma}, k_{4}^{\gamma \delta c}, m_{1 j}^{\alpha}, m_{2 b}^{\beta}, m_{3 c}^{\gamma}, m_{4 d}^{\delta} \geq \\
& 0 \text { integer, } \forall \alpha, \beta, \gamma, \delta, i, j, b, c, d \\
& Q_{\mathrm{i}} \geq 1 \quad \text { integer, } \forall i
\end{aligned}
$$

Equation (6) is related to the storage space per process. Equation (7) shows that the lot size of the preceding process is greater than or equal to the lot size of the next process. Equation (8) demonstrates the inventory balance constraint that the sum of the initial inventory and production must be greater than the sum of the safety inventory level and shipment. Equation (9) shows that the quantity of products entering the production process must be equal to the number of quantity at the time of production completion. Equation (10) relates to the BOM, and Equations (11) and (12) show that the maximum production per line cannot be exceed. The constraint in Equation (13) indicates that the raw material or semi-finished product is produced as a semi-finished and finished product in a specific blank, press, or 
DongJ in Jin, MoonHyeung Lee, ByungDo Chung; Optimization of a Joint Economic Lot Size Model for a First-tier Supplier with Sequential Processes Using a Genetic Algorithm. Transactions on Machine Learning and Artificial Intelligence, Volume 6 No 5 October (2018); pp: 28-42

assembly line. Finally, Equation (14) limits the number of production and delivery times, and the decision variable has a non-negative integer value. In addition, lot sizes have an integer value greater than 1.

\section{Algorithm}

\subsection{Algorithm Description}

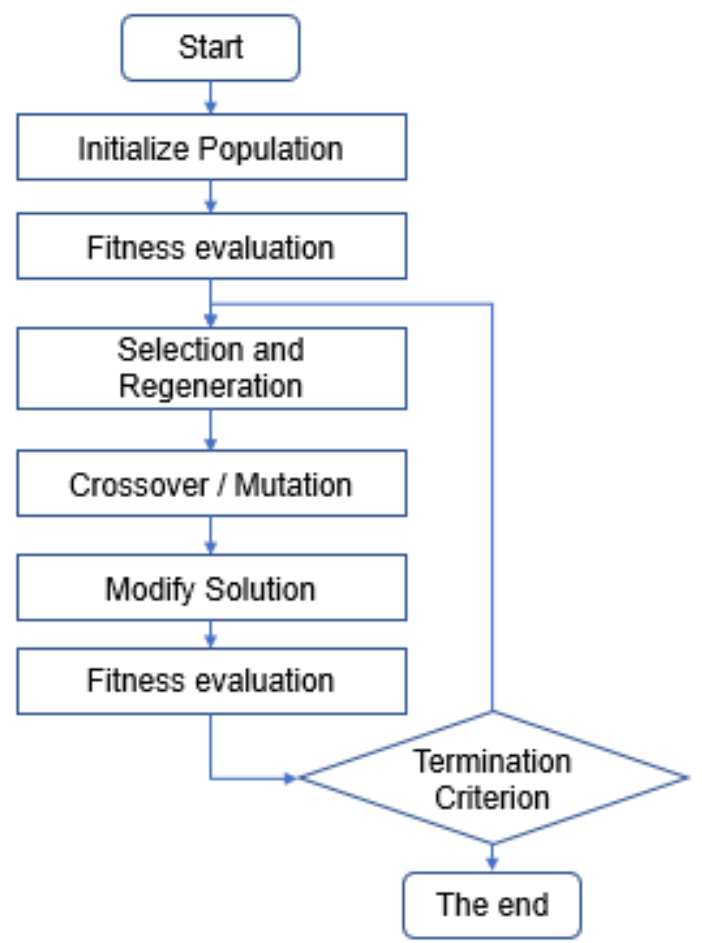

Figure 3. Algorithm flow chart

\begin{tabular}{|c|c|c|c|c|c|c|c|c|c|}
\multicolumn{9}{|c}{ Lot size } & \multicolumn{2}{c}{$\begin{array}{c}\text { The number } \\
\text { of production }\end{array}$} \\
\hline Lot1 & Lot2 & Lot3 & Lot4 & $\mathrm{k} 11$ & $\mathrm{k} 12$ & $\ldots$ & $\ldots$ & $\mathrm{m} 41$ & $\mathrm{~m}$ The number \\
of delivery
\end{tabular}

Figure 4. Chromosome expression

We propose a genetic algorithm to solve the NLP problem. A flowchart of the algorithm used in this study is shown in Figure 3. The chromosome comprises the actual values of the decision variables, as shown in Figure 4. The first line shows the location and meaning of the decision variable, and the second line shows the actual value of the decision variable used in the algorithm.

The initial solution is generated as follows: First, the lot size of the assembly process is calculated as a multiple of the pallet size, and the lot size of the press process is then calculated as a multiple of the lot size of the assembly process. When the lot size of the press process is determined, the lot size of the blank process can be calculated in the same manner, and the lot size of the raw material supplier can be 
obtained. The reason for using a multiple is to make the decision variables have integer values. The reason for using integers is that if one lot is used at the factory, it will not be possible to interrupt the work within the lot in use and proceed with other work. The lot size is determined in the following manner, and the number of production and delivery is determined by the constraints that the modeling reflects. For example, in the assembly process, the quantity delivered per item must be greater than or equal to the OEM demand; thus, the number of deliveries can be determined. In addition, the number of production through assembly can be calculated by the inventory balancing constraint. The number of deliveries of the press can be obtained because of the constraint that the input quantity to the assembly process is equal to the output quantity. Likewise, we can obtain the number of production and delivery for all processes. We calculate the lot size, the number of production, and the number of delivery to complete a single solution.

Next, we evaluate the fitness of each initial solution based on the initial 20 solutions. The fitness uses the reciprocal of the cost. This is because fitness increases as costs decrease. Owing to the fitness assessment, 10 solutions, $50 \%$ of previous generations' good solutions, survive in the next generation, and the remaining $50 \%$ of solutions are regenerated using the initial solution generation method.

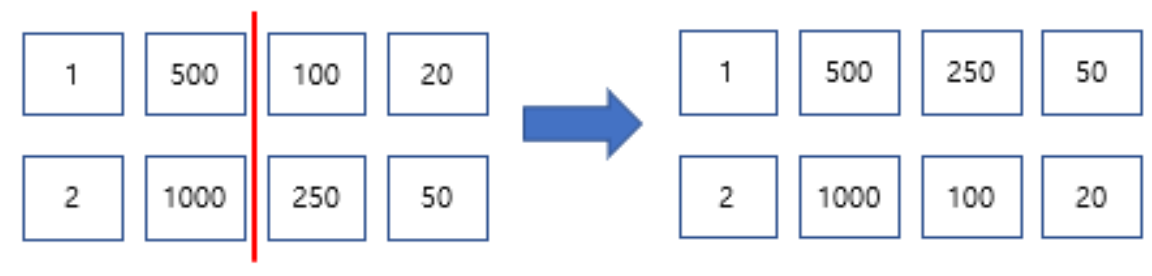

Figure 5. One-point crossover

The crossover operator is performed using the next-generation solution created through selection and playback. The crossover method uses a one-point crossover. In addition, the crossover method uses only 4 lot sizes. The reason is that if the lot size changes, the number of production and delivery will change. The crossover method randomly selects two solutions from the population and determines the location of the lot size for intersection. It then intersects the two solutions at this location. For example, the crossover operator is shown in Figure 5. The red line indicates the point at which the one-point crossover is performed and indicates that the two-parent solutions of $[1,500,100,20]$ and $[2,1,000,250,50]$ are changed to two offspring solutions of $[1,500,250,50]$ and $[2,1,000,100,20]$.

In the mutation operator, one solution is selected from the population in which the crossover has progressed. Next, we select the lot size that one randomly would want to change for the selected solution and change the lot size. The mutation proceeds by changing the lot size of selected process to an arbitrary value that satisfies a divisor relation to the lot size of the previous process and a multiple relation to the lot size of the next process. This is because all decision variables must have integer values. Once the lot size is determined, the number of production and delivery is determined to satisfy the constraint, and all solutions in the population will have a feasible solution.

In the modify solution, a local search is performed with the population in which the crossover and mutation operators have been carried out. We select one solution from the population and choose one lot size from among the four lot sizes. We then change all of the lot sizes of the selected processes to determine the lot size value that satisfies a divisor relation to the lot size of previous processes and a 
DongJ in Jin, MoonHyeung Lee, ByungDo Chung; Optimization of a Joint Economic Lot Size Model for a First-tier Supplier with Sequential Processes Using a Genetic Algorithm. Transactions on Machine Learning and Artificial Intelligence, Volume 6 No 5 October (2018); pp: 28-42

multiple relation to the lot size of the next process. Then, we calculate the number of production and delivery. In this way, we can create multiple solutions with a divisor multiple relationships and replace the originally selected solution with a modified solution with the best fitness value.

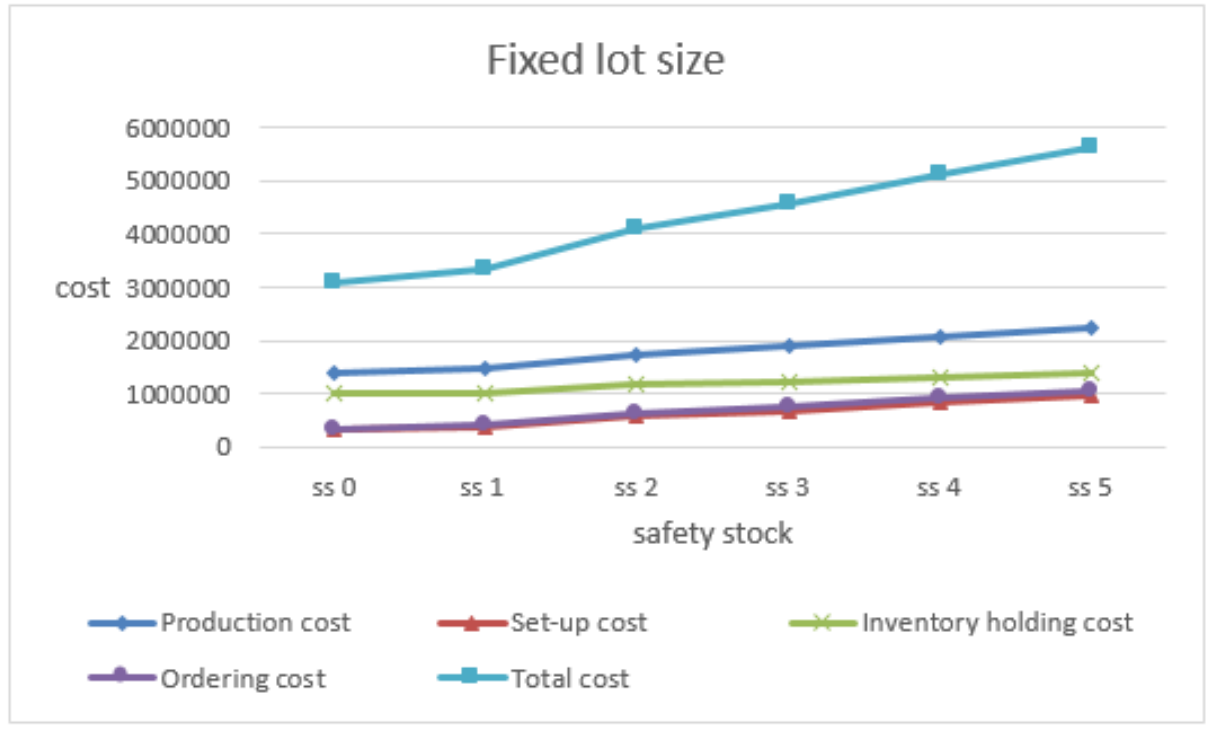

Figure 6. Fixed lot size

After performing the modify solution steps, all 20 solutions are evaluated for fitness. In this step, we assess the fitness of each solution and stored the best solution. Once all the preceding steps are completed, we check the algorithm's termination condition, and it then terminated when the same best solution was repeated 20 times or when the number of repetitions reached 500 . Otherwise, we increased the number of iterations by 1 and returned to the selection and regeneration stage and repeat the process.

\section{Experiment Results}

After formalizing the NLP model, we using a genetic algorithm to solve the NLP model and explain the experimental results. The cost data included in the experiment were used for the following reasons: The production cost per unit was calculated with respect to the product production time. Production time was based on the actual first-tier supplier's production time. However, because the coil, the raw material, is assumed to produce 500 blank products using a one coil, the production cost of the coil was multiplied by 500 to determine the production cost of the blanking product. The setup cost per lot was based on the setup time used by the actual first-tier supplier process. Inventory holding costs were calculated as the volume of individual products. We assume that the same volume per lot was used for each process. The volume is used as the number of products per lot divided by the number of products in the palette. Finally, the ordering cost per lot is the number of individual products included in the lot. The volume, quantity, time, and the actual lot size used here were based on actual first-tier suppliers.

First, some real companies use the fixed lot size. However, if demand or safety stock levels change, using fixed lot sizes may result in inefficiencies. Hence, we compared the case of taking the lot size fixedly and the case of taking the lot size dynamically. We ran an experiment on two cases and checked for cost changes. 


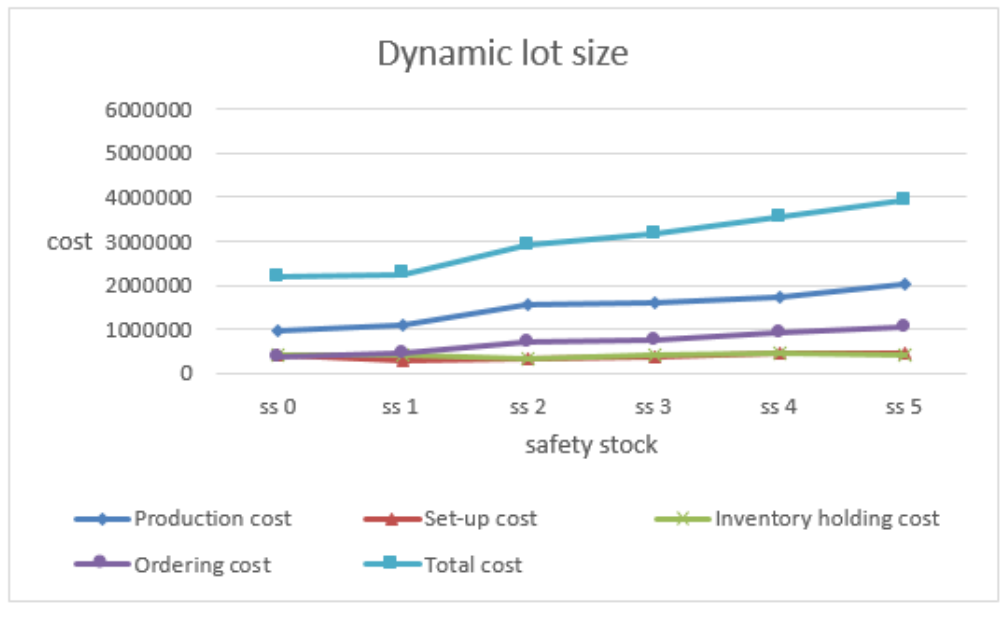

Figure 7. Dynamic lot size

Figures 6 and 7 show a comparison between the fixed lot size and the dynamic lot size. In the Figures 6 and 7, ss 0 represents the result of setting the safety inventory level to 0; ss 1 represents the result of setting the safety inventory level to 1 day, and ss $2,3,4$, and 5 represent the result of setting the safety inventory level to $2,3,4$, and 5 days, respectively. The meaning of safety inventory level 1 is set to the production quantity of one day.

The results of the experiment are as follows. We compared the use of fixed lot sizes and the use of dynamic lot sizes. Using a dynamic lot size rather than a fixed lot size reduces the total cost. The reason for this is that it changes the lot size to determine the lot size of the lowest cost. Experiments were performed while increasing the level of safety inventory. Figures 6 and 7 show that the difference between the total cost and the other costs increased slightly when using the dynamic lot size, while the fixed lot size showed a sharp increase in the difference. if one uses a fixed lot size, the higher the safety stock level, the higher the cost; thus, a dynamic lot size is better than fixed a one if a safety stock is needed.

Second, because settings are important in real companies, we experimented to determine how shortening the setup time can affect the cost and lot size. The experiment identified changes in other costs and lot sizes while changing the setup cost.

Table 4. Cost of changing the setup

\begin{tabular}{|c|c|c|c|c|c|c|c|c|}
\hline & \multicolumn{7}{|c}{ Change in setup cost } & $1 / 10$ \\
\hline & 10 & 7 & 5 & 3 & 1 & 0.9 & 0.8 & Ratio \\
\hline $\begin{array}{c}\text { Production } \\
\text { cost }\end{array}$ & $1,623,000$ & $1,539,000$ & $1,285,200$ & $1,077,000$ & $1,077,000$ & $1,077,000$ & $1,077,000$ & $\begin{array}{c}0.66 \\
(-34 \%)\end{array}$ \\
\hline Setup cost & $1,872,000$ & $1,386,000$ & $1,183,500$ & 710,100 & 299,700 & 269,730 & 239,760 & $\begin{array}{c}0.16 \\
(-84 \%)\end{array}$ \\
\hline $\begin{array}{c}\text { Ordering } \\
\text { cost }\end{array}$ & 261,180 & 274,680 & 330,480 & 330,480 & 415,080 & 415,080 & 415,080 & $\begin{array}{c}1.59 \\
(+59 \%)\end{array}$ \\
\hline $\begin{array}{c}\text { Holding } \\
\text { cost }\end{array}$ & $500,464.50$ & $490,009.50$ & $481,564.50$ & $481,564.50$ & 466,077 & 466,077 & 466,077 & 0.93 \\
$(-7 \%)$
\end{tabular}


DongJ in Jin, MoonHyeung Lee, ByungDo Chung; Optimization of a Joint Economic Lot Size Model for a First-tier Supplier with Sequential Processes Using a Genetic Algorithm. Transactions on Machine Learning and Artificial Intelligence, Volume 6 No 5 October (2018); pp: 28-42

Table 5. Lot size according to the setup cost change

\begin{tabular}{|c|c|c|c|c|c|c|c|}
\hline & \multicolumn{7}{|c|}{ Change in setup cost } \\
\hline & 10 & 7 & 5 & 3 & 1 & 0.9 & 0.8 \\
\hline $\begin{array}{l}\text { Lot size of } \\
\text { raw } \\
\text { material } \\
\text { process }\end{array}$ & 27 & 27 & 27 & 27 & 26 & 26 & 26 \\
\hline $\begin{array}{l}\text { Lot size of } \\
\text { blank } \\
\text { process }\end{array}$ & 13,500 & 13,500 & 13,500 & 13,500 & 13,000 & 13,000 & 13,000 \\
\hline $\begin{array}{c}\text { Lot size of } \\
\text { press } \\
\text { process }\end{array}$ & 500 & 450 & 300 & 300 & 200 & 200 & 200 \\
\hline $\begin{array}{c}\text { Lot size of } \\
\text { assembly } \\
\text { process }\end{array}$ & 100 & 90 & 100 & 100 & 100 & 100 & 100 \\
\hline
\end{tabular}

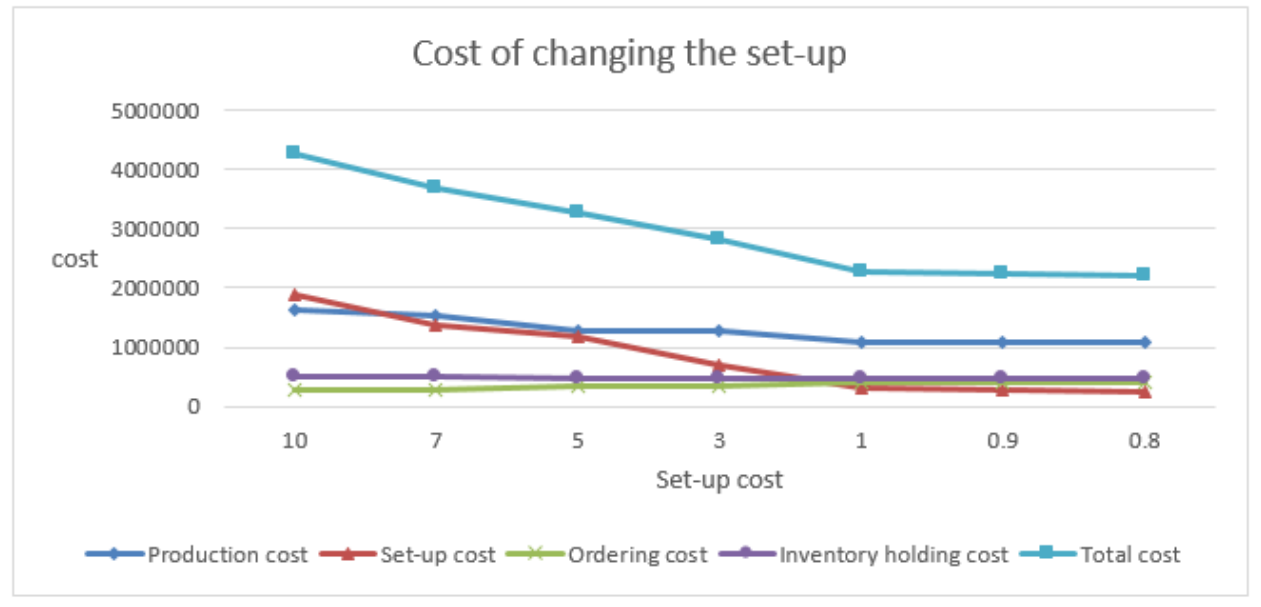

Figure 8. Cost of the changing setup

Figure 8 and Table 4 show changes in costs due to changes in the setup cost, and Table 5 shows changes in lot size due to changes in the setup cost. The change in the setup cost in Tables 4 and 5 indicates that the parameter value of the other cost is fixed and that only the parameter value of the setup cost is changed. For example, 10 is the result of a 10-fold increase in setup costs, while other costs are fixed, and 1 is the initial cost without any changes. The ratio represents the value of 1 divided by 10 in the setup cost change. If the ratio is greater than 1 , the cost is increased. If the ratio is less than 1 , the cost is decreased. Finally, the sum of the other costs is the total sum of the costs, excluding the setup costs.

The experimental results are as follows. Reducing the setup cost will reduce the production cost by $34 \%$, inventory holding cost by $7 \%$, and total cost by $47 \%$. In addition, the sum of the remaining cost and the setup cost is reduced. Reducing the setup cost from 10 to 1 reduces the sum of the remaining costs by $18 \%$. On the other hand, the ordering cost will increase by $59 \%$. This is because the lot size becomes smaller as the setup cost decreases. For example, when reducing the setup cost from 10 to 1 , the production cost decreases from 1,623,000 to 1,077,000, which means that the production cost is reduced by $34 \%$. In addition, if the setup cost is reduced from 10 to 1 , then the inventory holding cost is reduced 
from $500,464.5$ to 466,077 , which means that the inventory holding cost decreases by $7 \%$. Moreover, if the setup cost is decreased from 10 to 1 , then the ordering cost increases from 261,180 to 415,080, which means that the ordering cost increases by $59 \%$. Also, if the setup cost is decreased from 10 to 1 , the sum of the other cost (excluding the setup cost) is reduced from 2,384,645 to $1,958,157$, which means that the sum of the other cost is reduced by $18 \%$.

In addition, even if the setup cost is reduced, the lot size is the same if it falls below a certain level. For example, if the setup cost change is 10 , the lot size is $[27,13,500,500,100]$, and if it is 1 , it is reduced to $[26,13,000,200,100]$. On the other hand, for 0.9 and 0.8 , the lot size is the same as 1 for $[26,13,000$, $200,100]$. It is therefore important to find and manage specific levels.

\section{Conclusion}

This study analyzes the lot size of a three stage supply chain comprising raw material suppliers, first-tier suppliers, and OEMs. To the best of our knowledge, there is no paper has considered the assembly line in an integrated supply chain. Some automobile first-tier suppliers assemble parts in the final assembly process to make the finished product. In this study, we built a supply chain comprising several products with assembly lines, unlike most previous research considering a single product. Most JELP research have not considered outsourcing or shipping between production processes; however, we consider outsourcing or shipping products between production processes. Therefore, the contributions of this paper are that it conducts an analysis of a supply chain that includes the assembly process and that it considered outsourcing and semi-finished products between the first-tier supplier processes.

We propose an NLP model and solve the problem by using a genetic algorithm. The results are based on scenarios. First, using a dynamic lot size rather than a fixed lot size reduces the total cost. In addition, as the level of safety inventory increases, the gap between the total cost and other costs slightly increases. Second, if one can shorten setup costs by reducing the setup time, the lot size will be smaller, and the total cost will be lower. However, if the lot size falls below a certain level, the lot size will be the same even if the setup cost is reduced. It is therefore important to find and manage specific levels of costs.

The future research directions of our study are as follows. This study accounts for the multilevel supply chain of a single company; thus, the number of participants analyzed can be increased. It is also possible to increase the number of items or lines in the supply chain. Finally, the present research can be extended to a problem that considers uncertain situations.

\section{ACKNOWLEDGMENTS}

This work was supported by the World Class 300 Project (R\&D) (Project number S2482274, Development of Multi-Vehicle Flexible Production Platform for Future Smart Body Factory (2/5)) of the MOTIE, MSS (Korea).

\section{REFERENCES}

[1] GOYAL, S. K. An integrated inventory model for a single supplier-single customer problem. The International Journal of Production Research, 1977, 15.1: 107-111. 
DongJ in Jin, MoonHyeung Lee, ByungDo Chung; Optimization of a Joint Economic Lot Size Model for a First-tier Supplier with Sequential Processes Using a Genetic Algorithm. Transactions on Machine Learning and Artificial Intelligence, Volume 6 No 5 October (2018); pp: 28-42

[2] BANERJEE, Avijit. A joint economic-lot-size model for purchaser and vendor. Decision Sciences, 1986, 17.3: 292-311.

[3] HILL, Roger M. The optimal production and shipment policy for the single-vendor single buyer integrated production-inventory problem. International Journal of Production Research, 1999, 37.11: 2463-2475.

[4] TALEIZADEH, Ata Allah; NIAKI, Seyed Taghi Akhavan; BARZINPOUR, Farnaz. Multiple-buyer multiplevendor multi-product multi-constraint supply chain problem with stochastic demand and variable leadtime: a harmony search algorithm. Applied Mathematics and Computation, 2011, 217.22: 9234-9253.

[5] LEE, Wenyih. A joint economic lot size model for raw material ordering, manufacturing setup, and finished goods delivering. Omega, 2005, 33.2: 163-174.

[6] MUNSON, Charles L.; ROSENBLATT, Meir J. Coordinating a three-level supply chain with quantity discounts. IIE Transactions, 2001, 33.5: 371-384.

[7] WANG, Shaojun; SARKER, Bhaba R. Optimal models for a multi-stage supply chain system controlled by kanban under just-in-time philosophy. European Journal of Operational Research, 2006, 172.1: 179-200.

[8] KHOUJA, Moutaz. Optimizing inventory decisions in a multi-stage multi-customer supply chain. Transportation Research Part E: Logistics and Transportation Review, 2003, 39.3: 193-208.

[9] JABER, M. Y.; GOYAL, S. K. Coordinating a three-level supply chain with multiple suppliers, a vendor and multiple buyers. International Journal of Production Economics, 2008, 116.1: 95-103.

[10] BEN-DAYA, M.; AL-NASSAR, A. An integrated inventory production system in a three-layer supply chain. Production Planning and Control, 2008, 19.2: 97-104.

[11] ADEINAT, Hamza; VENTURA, José A. Integrated pricing and lot-sizing decisions in a serial supply chain. Applied Mathematical Modelling, 2018, 54: 429-445.

[12] LIM, I. J.; PARK, K. S.; KIM, J. H. Determining Optimal Lot Size for Batch Processes Using TOPSIS. Management Education Research, 2015, 30: 163-185. 